\section{Germination and Regeneration of Plants from Old Cucumber Seed}

\author{
Nawab Ali, Robert Skirvin, Walter E. Splittstoesser, and \\ William L. George \\ Department of Horticulture, University of Illinois, Urbana, IL 61801
}

Additional index words. Cucumis sativus, cotyledons, growth regulators, seed aging, tissue culture

Abstract. Cucumber (Cucumis sativus L.) seeds of 'Marketer', 'Marketmore', 'Wisconsin SMR-18', 'Tablegreen', 'Spotfree', and 'China' were stored at $3 \mathrm{C}$ and $38 \%$ relative humidity for up to 26 years. Seed older than 13 years did not germinate. Cultivars stored 10 years gave $80 \%$ germination, except Wisconsin SMR-18' (40\%). Ten-year-old seeds were separated from their seedcoats, and cotyledons were excised into six segments. Explants were placed on Murashige and Skoog medium with all combinations of BAP $\left(0,1,2\right.$, and $\left.3 \mathrm{mg}^{-1 i t e r}{ }^{-1}\right)$ and NAA $\left(0,0.1,0.2\right.$, and $\left.0.3 \mathrm{mg}^{-l i t e r}{ }^{-1}\right)$. Plants were obtained from culture for all cultivars grown on medium containing NAA and $1 \mathrm{mg}$ BAP/liter. No plants were regenerated when BAP or NAA was lacking. Chemical names used: benzylaminopurine (BAP), 1-naphthaleneacetic acid (NAA).

Seed storage is important for germplasm preservation, and most cucumber germplasm is stored as seed. Seed may be stored for decades, depending upon the storage conditions. No matter how good the seed storage is, seeds are likely to lose viability with age. The germplasm must be renewed regularly, requiring considerable land and labor (Roos, 1980). Irreversible degenerative changes during storage eventually result in death of the seeds (Roberts, 1972).

A tissue culture system that would enable successful regeneration from mature, excised dry seed pieces would offer a means to multiply plants rapidly when only a small amount of seed is available. Shoot regeneration and embryogenesis from cucumber cotyledons (Cade et al., 1987; Chee, 1990) and several Cucurbita species (Lange and Juvik, 1986a) has been reported. In this paper, we report the germination and regeneration in tissue culture of entire plants from cucumber cotyledons excised from aged seeds.

Seeds of 'Marketer', 'Marketmore', 'Wisconsin SMR-18', 'Tablegreen', 'Spotfree', and 'China', which were 26, 20, 18, 17, 16, 15,13 , and 10 years old, were stored at $3 \mathrm{C}$ and $38 \%$ relative humidity $(\mathrm{RH})$ from harvest until use. Seeds (five) of each cultivar and age were germinated in petri dishes with Whatman \#1 filter paper. Water was added and the seeds incubated for 10 days at 20C. Radicle emergence ( $5 \mathrm{~mm}$ long) was used as the indicator of germination. The size of these experiments was limited due to the few seeds available for the older lots.

For regeneration studies, the outer seedcoat was removed from five seeds from each of 13- and 10-year-old lots, sterilized in 70\% ethanol for $1 \mathrm{~min}$, in $0.5 \%$ sodium hypochlorite for $10 \mathrm{~min}$, and rinsed three times

Received for publication 4 June 1990. The cost of publishing this paper was defrayed in part by the payment of page charges. Under postal regulations, this paper therefore must be hereby marked advertisement solely to indicate this fact. with sterilized distilled water. Cotyledons were separated aseptically and then divided into three segments such that each seed provided six cotyledon segments. Ali (1990) had shown that cotyledon size was not a factor in plant regeneration, and the six cotyledon segments were kept as a unit to provide repetition.

The 30 cotyledon segments from each cultivar were randomly explanted onto Murashige and Skoog (1962) medium (MS) with agar (8 g.liter $)$ and BAP (4 mg.liter $\left.{ }^{-1}\right)$ and NAA (0.2 mg.liter $\left.{ }^{-1}\right)$ (Msikita et al., 1990). The $\mathrm{pH}$ was adjusted to 5.7 with $\mathrm{KOH}$ before autoclaving. An additional four seeds per treatment from each cultivar harvested in 1978 were sterilized as above, cut into four cotyledon sections per seed, and placed on
Table 1. Plant regeneration from old cucumber cotyledons. ${ }^{z}$ BAP and NAA. ${ }^{2}$
MS medium with agar with $0,1,2$, or $3 \mathrm{mg}$ $\mathrm{BAP} /$ liter and $0,1,2$, or $3 \mathrm{mg}$ NAA/liter in all possible combinations in a $4 \times 4$ factorial design. The experiment was replicated three times and evaluated every 15 days. Shoots longer than $10 \mathrm{~mm}$ were removed and placed in rooting medium. The remaining explant was subculture in identical fresh medium.

For rooting, shoots were transferred to MS medium supplemented only with $1.5 \mathrm{mg}$ NAA/liter. Shoots that rooted were moved to soil in 0.1-liter plastic pots, covered with a sheet of plastic, and grown in the culture room. After 1 week, the plastic was removed, and plants were moved to the greenhouse. In all regeneration studies, values presented included only those of shoots that grew, rooted, and survived to become a whole plant in soil. Although many small shoots formed, these were not recorded because they did not survive and regenerate plants.

Seeds more than 13 years old did not germinate. Although the seeds were stored under similar conditions, there was variation among cultivars in their ability to germinate. 'Tablegreen' seeds failed to germinate after 13 years, whereas 'Marketmore' had 40\% germination. With 10-year-old seeds, 'Wisconsin SMR-18' had 40\% germination and all other cultivars had $80 \%$ or more. Variation in germination percentage occurs among cucumber cultivars (James et al., 1967). Bewley and Black (1982) reported 90\% to $100 \%$ viability for 5-year-old cucumber seeds stored at $50 \% \mathrm{RH}$ and $10 \mathrm{C}$. The seeds used in this study were older and of different cultivars.

Cotyledons from cultivars that did not germinate did not regenerate in vitro. Plants were regenerated from cotyledons of fresh (data not shown) or 10-year-old seeds (Table 1). Some explants produced callus, while others

\begin{tabular}{lcccc}
\hline \hline Cultivar & $\begin{array}{c}\text { Seed } \\
\text { age } \\
\text { (year) }\end{array}$ & $\begin{array}{c}\text { Survival } \\
\text { of } \\
\text { cotyledons } \\
\text { (days) }\end{array}$ & $\begin{array}{c}\text { Explants } \\
\text { forming } \\
\text { callus } \\
(\%)\end{array}$ & $\begin{array}{c}\text { Plants } \\
\text { regenerated } \\
\text { (no.) }\end{array}$ \\
\hline Marketer & 10 & 55 & 0 & 3 \\
Marketmore & 10 & 30 & 0 & 0 \\
Wisconsin SMR-18 & 13 & 65 & 10 & 9 \\
Tablegreen & 10 & 29 & 10 & 0 \\
Spotfree & 10 & 32 & 0 & 1 \\
China & 10 & 44 & 40 & 19 \\
\hline
\end{tabular}

${ }^{z}$ Explants on MS media with $4 \mathrm{mg} \mathrm{BAP} /$ liter and $0.2 \mathrm{mg}$ NAA/liter.

Table 2. Plant regeneration from cotyledons of 10 -year-old cucumber seed in nine combinations of

\begin{tabular}{|c|c|c|c|c|c|c|c|c|c|}
\hline \multirow[b]{4}{*}{ Cultivar } & \multicolumn{9}{|c|}{ BAP $\left(\mathrm{mg} \cdot\right.$ liter $\left.^{-1}\right)$} \\
\hline & \multicolumn{3}{|c|}{1} & \multicolumn{3}{|c|}{2} & \multicolumn{3}{|c|}{3} \\
\hline & \multicolumn{9}{|c|}{ NAA (mg-liter ${ }^{-1}$ ) } \\
\hline & 0.1 & 0.2 & 0.3 & 0.1 & 0.2 & 0.3 & 0.1 & 0.2 & 0.3 \\
\hline Marketer & 2 & 2 & 1 & 0 & 0 & 0 & 0 & 0 & 2 \\
\hline Marketmore & 0 & 2 & 0 & 0 & 1 & 3 & 1 & 2 & 1 \\
\hline Wisconsin SMR-18 & 0 & 2 & 0 & 0 & 0 & 1 & 0 & 0 & 0 \\
\hline Tablegreen & 3 & 0 & 0 & 0 & 0 & 1 & 2 & 1 & 1 \\
\hline Spotfree & 2 & 0 & 0 & 0 & 0 & 0 & 0 & 0 & 0 \\
\hline China & 5 & 0 & 2 & 1 & 1 & 2 & 5 & 0 & 3 \\
\hline
\end{tabular}

"No plants were regenerated when the medium lacked BAP or NAA. 
did not; recently, Chee (1990) reported that only 5\% of the explants from 'Poinsett 76' cucumber cotyledons formed embryonic callus. In this study, shoots $<10 \mathrm{~mm}$ long seldom survived ex vitro. In general, the number of shoots that survived ex vitro was directly proportional to the length of time the explant survived in vitro (Table 1). Cotyledons of 'China' survived the longest and regenerated the most plants; 'Spotfree' survived the shortest and produced only one plant. Cotyledons of other cultivars turned green and expanded but survived for 32 days or less and produced no plants. Cotyledons from nonviable seed lots did not develop chlorophyll or callus.

The seeds used here were about the same age, but there was a wide range of regeneration frequencies (Table 1). Variation in regenerability among cultivars has been reported for cucumber (Lange and Juvik, 1986b; Msikita et al., 1988) and other cucurbits (Lange and Juvik, 1986a). In this study, 'Wisconsin SMR-18', a monoecious line, did not regenerate shoots. Alvarez (1989) reported more ethylene was produced by 'Wisconsin 98', a gynoecious cucumber, compared to monoecious lines. Seed-generated ethylene may have restricted regeneration of 'Wisconsin SMR-18' in vitro.

Seed aging reduced in vitro regenerability more than viability. Thirteen-year-old 'Marketmore' seeds germinated $40 \%$, and cotyledon explants turned green in vitro, but they failed to yield plants ex vitro. In contrast, 10year-old 'Marketmore' seeds germinated $80 \%$ and yielded nine plants (Table 1). Regeneration of plants from cucumber cotyledon culture varies among genotypes (Malepszy and Orczyk, 1983; Msikita et al., 1988).

Seeds older than 13 years did not germinate, but these seeds might possess islands of living cells that might regenerate in vitro with the proper stimulus of growth regulators. However, nonviable seeds failed to regenerate. Among viable ones, none regenerated on medium lacking in either BAP or
NAA (data not presented). At the lowest level of BAP (1 mg.liter $\left.{ }^{-1}\right)$, all cultivars produced some shoots that rooted and grew as plants ex vitro (Table 2). At $2 \mathrm{mg}$ BAP/liter, 'Marketer' and 'Spotfree' did not regenerate, and at $3 \mathrm{mg} \mathrm{BAP/liter,} \mathrm{'Wisconsin} \mathrm{SMR-18'} \mathrm{and}$ 'Spotfree' did not regenerate (Table 2). 'China' and 'Marketmore' responded to a wide concentration of growth regulators (Table 2), and 'China' regenerated well even at $4 \mathrm{mg} \mathrm{BAP} / \mathrm{liter}$ (Table 1).

'China' regenerated over a wide range of BAP (1 to $3 \mathrm{mg} \cdot$ liter $^{-1}$ ) and NAA (0.1 to $0.3 \mathrm{mg} \cdot$ liter $\left.^{-1}\right)$ combinations. With an increase from 1 to $3 \mathrm{mg}$ BAP/liter, 'Marketmore' regenerated over the entire range of NAA concentrations (Table 2). Similar reports for varioius cucurbits have been made by Dirks and Buggenum (1989), Msikita et al. (1988), and Pink and Walkey (1984). Mackay and Ng (1989) reported that shoot count in Cucumis melo decreased as NAA level increased, but in this study with cucumber, no such pattern of NAA inhibition was found. Chee (1990) recently reported somatic embryogenesis induced from cucumber cotyledons on MS medium with (2,4dichlorophenoxy) acetic acid (2,4-D; 2.0 mg.liter $\left.{ }^{-1}\right), \mathrm{N}$-(2-furanylmethyl)- 1H-purin-6amine (kinetin, $0.5 \mathrm{mg} \cdot \mathrm{liter}^{-1}$ ), and NAA $\left(1.0 \mathrm{mg} \cdot\right.$ liter $\left.^{-1}\right)$. In our study, we moved our regenerates to rooting medium supplemented with NAA only (1.5 $\mathrm{mg} \cdot$ liter $\left.^{-1}\right)$.

\section{Literature Cited}

Ali, N. 1990. Regeneration and germination of cucumber seeds in vitro and a study of delayed germination gene $(d f)$. PhD Diss., Univ. of Illinois, Urbana.

Alvarez, J. 1989. Ethylene production by germinating seeds of different sexual genotypes of muskmelon (C. melo L.). Cucurbit Genet. Coop. Rpt. 12:117-141.

Bewley, J.D. and M. Black. 1982. Physiology and biochemistry of seeds in relation to germination. vol. 2. Springer-Verlag, New York.

Cade, R.M., T.C. Wehner, and F.A. Blazich.
1987. Organogenesis and embryogenesis from cucumber (C. sativus L.) cotyledon-derived callus. HortScience 22:1130.

Chee, P.P. 1990. High frequency of somatic embryogenesis and recovery of fertile cucumber plants. HortScience 25:792-793.

Dirks, R. and M.V. Buggenum. 1989. In vitro plant regeneration from leaf explants of $\mathrm{Cucu-}$ mis melo L, Plant Cell Rpt. 7:626-627.

James, E., L.N. Bass, and D.C. Clark. 1967. Varietal differences in longevity of vegetable seeds and their response to various storage conditions. Proc. Amer. Soc. Hort. Sci. 91:521528.

Lange, N.E. and J.A. Juvik. 1986a. Organogenesis from explants of mature seed cotyledons of 20 accessions from the genera Cucurbita, $\mathrm{Cu}$ cumis and Citrullus. HortScience 21:687.

Lange, N.E. and J.A. Juvik. 1986b. Age dependence for organogenesis of seed explants from four Cucurbita accessions. Cucurbit Genet. Coop. Rpt. 9:93-96.

Mackay, W.A. and T.J. Ng. 1989. Direct and indirect regeneration of Cucumis melo L. from cotyledon culture. Cucurbit Genet. Coop. Rpt. 12:55-57.

Malepszy, S. and A.N. Orcyzk. 1983. In vitro culture of C. sativus L. regeneration of plants from callus formed by leaf explants. Z. Pfl. Physiol. 111:272-276.

Msikita, W., R.M. Skirvin, J.A. Juvik, and W.E. Splittstoesser. 1988. In vitro regeneration and flowering of cucumber cultivars and lines cultured from excised seed. Cucurbit Genet. Coop. Rpt. 11:5-7.

Msikita, W., R.M. Skirvin, J.A. Juvik, W.E, Splittstoesser, and N. Ali. 1990. Regeneration and flowering in vitro of 'Burpless Hybrid' cucumber cultured from excised seed. HortScience 25:474-477.

Murashige, T. and F. Skoog. 1962. A revised medium for rapid growth and bioassays with tobacco tissue culture. Physiol. Plant. 15:474497.

Pink, D.A.C. and D.G.A. Walkey. 1984. Rapid propagation of Cucurbita pepo L. by culture of meristem tips. Scientia Hort. 24: 107-1 14.

Roberts, E.H. 1972. Viability of seeds. Chapman and Hall, London.

Roos, E.E. 1980. Physiological, biochemical and genetic changes in seed quality during storage. HortScience 15:781-784. 